\title{
Editorial: Special Issue on Segmentation and Targeting
}

The importance of segmentation and targeting in the marketing of financial services has long been recognised by our leading global and national companies, and so it is without apology that we dedicate a special issue of the Journal of Financial Services Marketing on precisely this topic. In this issue we publish a selected tranche of papers which were presented at the conference in London on Segmentation and Targeting in Financial Services Marketing in November 2000 and in Philadelphia in January 2001, bringing together a wealth of practitioner expertise from both sides of the Atlantic. This is certainly not to dismiss the highly valued research studies being undertaken by many at our universities, but it does enable us to showcase and focus on the cutting-edge work undertaken by practitioners and the contribution they continue to make to thinking and practice in the field.

We open the issue with a valuable contribution from Peter Furness of Furness Associates. In this paper he focuses on the tools and techniques for customer modelling in Customer Relationship Management (CRM). Having outlined three main types of customer modelling, he then demonstrates, in several cases, their practical applications. He concludes by emphasising the vital role customer modelling has to play in CRM, while at the same time highlighting some of the challenges and opportunities that this will bring in the future. Lorrie LiBrizzi of Hunter Business Group, examines grading as a practical tool to help companies manage customer relationships based on the economic worth of its customers. The author supports her argument with a fascinating case study of an educational marketer, and illustrates how grading has helped the company to maintain an extremely high level of customer retention. Howard Moskowitz and Bert Krieger of Moskowitz Jacobs Inc, combine existing and novel approaches to conjoint measurement to identify the key features of new insurance products and develop a greater understanding of the consumer. Again, the authors offer a practical approach in their analysis, with the aim of increasing learning and creating a better product.

Bryan Foss and Merlin Stone, both of IBM, aim to provide business-to-customer financial services companies with lessons on the relevance of business-to-business segmentation from intermediated markets. E-business examples are highlighted, as is the developing role of e-markets in business-to business. Focusing on some of the challenges of e-business the authors provide a useful checklist for action to maintain customer profitability. John Hymas of Macon Consulting explores the complex relationship between the Internet and electronic channels and the customer. By focusing on a model of best practice customer management principles, Hymas points to the need for companies to blend the dynamic qualities of both the 'virtual' and the 'real' world in response to the changing needs of the customer. Caroline Kimber of CACI Ltd, continues the theme by examining the strategic integration of customers and channels, and outlines two new market-specific tools designed to aid financial services organisations in quantifying this demand. The battle between bricks and mortar financial institutions and e-finance are well 
illustrated and important examples from the US markets are drawn.

David Roscoe's experience as the Managing Director of Prophit Share has produced an interesting paper by looking at CRM in terms of developing one-toone relationships with the customers. The reader is taken on a step-by-step guide through the customer knowledge journey to develop a deeper understanding of the needs of individual customers. The upshot of this which is both an opportunity and challenge - is that there is a greater responsibility for the companies to deliver their 'brand promise'.

Andrew Lowe presents an impressive case study on how Fleming Premier Banking, a retail telephone bank, created an integral approach to its communications with clearly identified target customers and how this presents challenges of implementation in practice. The results show, however, a significant success rate for the company by using an integrated approach to communication.
The legal obligations for the financial services industry cannot be ignored, and therefore we conclude the special issue with an important paper by Shelagh Gaskill, Peter MacIntyre, William Malcolm and Adrian Hackett of Masons, outlining the legislation regarding the direct marketing of financial services. This will serve as a key reference source for all financial service marketers when examining the legal aspects of their work.

We hope that you enjoy this special issue on segmentation and targeting and find the range of papers both thought provoking and incisive. We would welcome any comments you may have on the papers published. Please note our next special issue will be on e-finance, with the call for papers included in this issue. Again, we look forward to your contributions in this changing field.
Kerry Barner Publishing Editor 
